\title{
dmLT Adjuvant Enhances Cytokine Responses to T Cell Stimuli, Whole Cell Vaccine Antigens and Lipopolysaccharide in Both Adults and Infants
}

\author{
Marjahan Akhtar ${ }^{1}$, Nuder Nower Nizam ${ }^{1}$, Salima Raiyan Basher ${ }^{1}$, Lazina Hossain ${ }^{1}$, \\ Sarmin Akter ${ }^{1}$, Taufiqur Rahman Bhuiyan ${ }^{1}$, Firdausi Qadri ${ }^{1}$ and Anna Lundgren ${ }^{2 *}$ \\ ${ }^{1}$ Infectious Diseases Division, icddr,b (International Centre for Diarrhoeal Disease Research, Bangladesh), Dhaka, Bangladesh, \\ 2 Department of Microbiology and Immunology, Institute of Biomedicine, University of Gothenburg, Gothenburg, Sweden
}

OPEN ACCESS

Edited by:

Fabio Bagnoli,

GlaxoSmithKline, Italy

Reviewed by:

TiLu,

University of Kansas, United States

Weiping Zhang,

University of Illinois at Urbana-

Champaign, United States

*Correspondence:

Anna Lundgren

anna.lundgren@microbio.gu.se

Specialty section:

This article was submitted to Vaccines and Molecular Therapeutics,

a section of the journal

Frontiers in Immunology

Received: 17 January 2021 Accepted: 19 April 2021

Published: 14 May 2021

Citation:

Akhtar M, Nizam NN, Basher SR,

Hossain L, Akter S, Bhuiyan TR,

Qadri F and Lundgren A (2021) dmLT

Adjuvant Enhances Cytokine

Responses to T Cell Stimuli, Whole

Cell Vaccine Antigens and

Lipopolysaccharide in Both

Adults and Infants.

Front. Immunol. 12:654872.

doi: 10.3389/fimmu.2021.654872
Enhancement of mucosal immune responses in children and infants using novel adjuvants such as double mutant heat labile toxin $(\mathrm{dmLT})$ is an important goal in the enteric vaccine field. $d m L T$ has been shown to enhance mucosal IgA responses to the oral inactivated enterotoxigenic Escherichia coli (ETEC) vaccine ETVAX. dmLT can enhance IL-17A production from adult $T$ cells, which may increase the production and secretion of mucosal IgA antibodies. However, the adjuvant mechanism remains to be fully elucidated and might differ between infants and adults due to age-related differences in the development of the immune system. The main objective of this study was to determine how dmLT influences antigen presenting cells and T cells from infants compared to adults, and the role of $\mathrm{IL}-1 \beta$ for mediating the adjuvant activity. Peripheral blood mononuclear cells (PBMCs) from Bangladeshi infants (6-11 months) and adults (18-40 years) were stimulated with the mitogen phytohaemagglutinin $(\mathrm{PHA})$, the superantigen Staphylococcal enterotoxin B (SEB), ETVAX whole cell component (WCC) or E. coli lipopolysaccharide (LPS) $\pm d m L T$, and cytokine production was measured using ELISA and electrochemiluminescence assays. The adjuvant dmLT significantly enhanced SEB- and PHA-induced IL-17A, but not IFN- $\gamma$ responses, in PBMCs from both infants and adults. Blocking experiments using an IL-1 receptor antagonist demonstrated the importance of IL-1 signaling for the adjuvant effect. dmLT, ETVAX WCC and LPS induced dosedependent IL-1 $\beta$ responses of comparable magnitudes in infant and adult cells. Depletion experiments suggested that IL-1 $\beta$ was mainly produced by monocytes. dmLT enhanced IL-1 $\beta$ responses to low doses of WCC and LPS, and the adjuvant effect appeared over a wider dose-range of WCC in infants. dmLT and WCC also induced IL-6, IL-23 and IL-12p70 production in both age groups and $\mathrm{dmLT}$ tended to particularly enhance IL-23 responses to WCC. Our results show that dmLT can induce IL-1 $\beta$ as well as other cytokines, which in turn may enhance IL-17A and potentially modulate other immunological responses in both infants and adults. Thus, dmLT may have an important 
function in promoting immune responses to the ETVAX vaccine, as well as other whole cell- or LPS-based vaccines in infants in low- and middle-income countries.

Keywords: dmLT, adjuvant, T cell, monocyte, infants, lipopolysacharide, IL-17A, IL-1 $\beta$

\section{INTRODUCTION}

Enteric infections are important causes of morbidity and mortality, particularly in young children in low and middleincome countries, but so far only a limited number of licensed vaccines exist against such infections (1-3). Oral vaccines induce immune responses locally in the gastrointestinal mucosa, but the responses are often lower in young children and infants compared to in adults $(1,4,5)$. Responses to oral vaccines are also generally lower in children in low-resource countries compared to in more developed parts of the world $(4,6)$. Therefore, enhancement of mucosal immune responses in children and infants using novel vaccine adjuvants that can be administered orally is an important goal in the field of enteric vaccination.

Enterotoxigenic Escherichia coli (ETEC) is one of the leading bacterial causes of watery diarrhea in children and infants in lowand middle-income countries. Several strategies are currently used to enhance the immunogenicity of ETEC vaccines, including the addition of the oral adjuvant double mutant heat-labile toxin (dmLT). Clements et al. developed dmLT from the heat labile toxin (LT) produced by ETEC and made it safe for use, without losing immunostimulatory properties, by altering two amino acids (R192G/L211A) in the enzymatically active A subunit of native LT (7-9). Oral administration of up to $250 \mu \mathrm{g}$ of dmLT did not cause any enterotoxicity in a mouse assay, while $\geq 5 \mu \mathrm{g}$ of native LT caused substantial intestinal fluid secretion (8). Importantly, dmLT has clear adjuvant properties, as demonstrated in several preclinical and clinical studies of mucosal vaccines, including ETEC, Helicobacter pylori and Streptococcus pneumoniae vaccines $(7,10-14)$. ETVAX is a leading oral ETEC vaccine candidate which consists of inactivated E. coli bacteria, overexpressing the four most prevalent ETEC colonization factors (CFs) CFA/I, CS3, CS5 and CS6, and a toxoid molecule $(12,13,15)$. Recent results from clinical trials of ETVAX demonstrate promising adjuvant effects of dmLT on IgA responses in adults, as well as children of different ages $(13,16)$. dmLT has also been shown to improve the protection afforded by an oral live attenuated ETEC vaccine in adults in an experimental challenge study (14).

The adjuvant mechanism of dmLT is not entirely elucidated, but effects on antigen processing and presentation in antigen presenting cells (APCs) are likely to be of critical importance (7, 17). Moreover, dmLT triggers activation of caspase1/ inflammasome signaling pathways and subsequently secretion

Abbreviations: APC, antigen presenting cell; dmLT, double mutant heat labile toxin; ETEC, enterotoxigenic Escherichia coli; IL-1RA, IL-1 receptor antagonist; LPS, lipopolysaccharide; LT, heat labile toxin; LTB, heat labile toxin B subunit; PBMCs, peripheral blood mononuclear cells; PHA, phytohaemagglutinin; SEB, Staphylococcal enterotoxin B; WCC, whole cell component. of IL-1 $\beta$, IL-23, IL-6 and other cytokines from APCs (7). These cytokines promote mixed Th1/Th2/Th17 responses in mice, with a particularly strong induction of Th17 cells (7). Importantly, Leach et al. and Larena et al. showed that dmLT, and the related multiple mutant cholera toxin (mmCT) adjuvant, can enhance human IL-17A cytokine responses in T helper cells from adults by activating cAMP-dependent protein kinase A and caspase1/ inflammasome-dependent IL-1 signaling $(18,19)$. IL-17A is particularly important in antibody-mediated protection against enteric infections, enhancing germinal center formation, IgA and IgG class switching and secretory IgA formation by increasing the expression of the poly-Ig receptor in epithelial cells (20-24).

Although infants and children are the main target groups for most enteric vaccines, the adjuvant mechanism of dmLT remains unexplored in these age groups. Both innate and adaptive immune cells in infants are immature or may function differently compared to adult cells (25-27). For example, immune cells from infants have been reported to have a higher baseline production of cAMP, as well as higher production of IL$1 \beta$ in response to some bacterial stimuli, compared to adult cells $(28,29)$, whereas production of several other cytokines (including IFN- $\gamma$ and TNF- $\alpha$ ) have consistently been reported to increase with age in infants and children (26). Ongoing efforts to evaluate the adjuvant function of $\mathrm{dmLT}$ in combination with different vaccines in different age groups, make it important to understand how the dmLT adjuvant may modulate immune responses in infants compared to adults.

In this study, we investigated if there are age-related differences in the capacity of the dmLT adjuvant to enhance cytokine responses in T cells and APCs, and analyzed the role of IL- $1 \beta$ for mediating the adjuvant function in infants compared to adults. We also analyzed if dmLT can modulate cytokine responses induced by the whole cell component (WCC) of ETVAX or E. coli lipopolysaccharide (LPS) in cells from adults and infants.

\section{METHODS AND MATERIALS}

\section{Study Participants}

Healthy Bangladeshi adults (18-40 years; $n=26)$ and infants (6-11 months; $\mathrm{n}=25$ ) were enrolled from similar socio-economic conditions (Table 1). Informed written consent was obtained from each adult participant and from parent/guardian of the infants. Participants were enrolled based on the clinical assessment of study physicians. Key exclusion criteria were history of gastrointestinal disorders, diarrheal or febrile illness during the last two weeks and antibiotic treatment within one week prior to enrollment. The studies were approved by the research review and ethical review committees of the International Centre for Diarrhoeal Disease Research, Bangladesh (icddr,b). 
TABLE 1 | Demographic characteristics of study participants.

\begin{tabular}{lcc}
\hline & Adults (n=26) & Infants (n=25) \\
\hline Age & $26.5(6.5)^{\mathrm{a}}$ & $8.5(1.8)^{\mathrm{b}}$ \\
Mean (SD) & $18-40^{\mathrm{a}}$ & $6-11^{\mathrm{b}}$ \\
Range & $7(27 \%)$ & \\
Gender (no. and freq. of participants) & $13(52 \%)$ \\
Male & $19(73 \%)$ & $12(48 \%)$ \\
Female & & \\
${ }^{a}$ Age in years. & & \\
${ }^{b}$ Age in months. &
\end{tabular}

\section{Specimen Collection and Processing}

Heparinized venous blood was collected on the day of enrollment. PBMCs were separated by density-gradient centrifugation using Ficoll-Isopaque (Pharmacia, Sweden). From subsets of participants, CD14+ monocytes were depleted from PBMCs using magnetic beads (Dynabeads, Dynal AS, Norway), according to the manufacturer's instructions. The frequencies of CD14+ monocytes in PBMCs after depletion were $<7 \%$ (mean $4 \%$ ) in all experiments, as determined by flow cytometric analysis.

\section{Antigens, Polyclonal Stimuli and Adjuvant}

PBMCs were stimulated with combinations of the following polyclonal stimuli, antigens, toxins or toxin derivatives: Staphylococcal enterotoxin B (SEB; Sigma-Aldrich, USA), phytohaemagglutinin (PHA, Remel, USA), E. coli O111:B4 LPS (Sigma Aldrich), dmLT (Scandinavian Biopharma, Sweden) and heat labile toxin B subunit (LTB, Scandinavian Biopharma). The cells were also stimulated with O78 LPS antigen, which was prepared in house from an enterotoxigenic O78 E. coli strain (H10407 P) by hot phenol water extraction followed by DNase and protease treatment, as described (30). The preparation contained less than $1 \%$ protein as determined by SDS page analyses using a standard protein as reference. Cells were also stimulated with a whole cell vaccine component (WCC, Scandinavian Biopharma, Etec970) corresponding to the composition of ETVAX, i.e. consisting of three formalininactivated O78 LPS-expressing LT and heat stabile toxin (ST) negative E. coli strains over-expressing CFA/I, CS3 and CS5 and one phenol inactivated E. coli K12 strain over-expressing CS6 $(12,13,15,16)$. The WCC did not contain any LCTBA or dmLT.

\section{Cell Stimulation}

Cells were cultured in DMEM F12 medium (Thermo Fisher Scientific, USA), supplemented with $50 \mathrm{mg} / \mathrm{mL}$ gentamicin and $5 \%$ human $\mathrm{AB}^{+}$serum, at $37^{\circ} \mathrm{C}$ in a $5 \% \mathrm{CO}_{2}$ incubator. PBMCs and PBMCs depleted of CD14+ monocytes $\left(10^{5}\right.$ cells/well) were cultured in duplicate wells in U-bottomed 96-well plates. Cells were left untreated or stimulated with SEB $(10 \mathrm{ng} / \mathrm{ml})$ or PHA (1 $\mu \mathrm{g} / \mathrm{ml}$ ) alone or in combination with increasing concentrations $(1 \mu \mathrm{g} / \mathrm{ml}$ or $10 \mu \mathrm{g} / \mathrm{ml})$ of dmLT or LTB. After $72 \mathrm{~h}$, supernatants were collected for cytokine analysis by ELISA (IL-17A and IFN$\gamma)$. For inhibition of IL-1 signaling, $1 \mu \mathrm{g} / \mathrm{ml}$ IL-1 receptor antagonist (IL-1RA, R\&D Systems, USA) was added daily for three days to cell cultures. For determination of production of IL$1 \beta$, IL-6, IL-23, IL-12p70, IL-10 and TFN- $\alpha$ PBMCs or PBMCs depleted of CD14+ monocytes were left untreated or stimulated for $18 \mathrm{~h}$ with LPS from E. coli O111:B4, ETEC O78 LPS (both 0.1-1000 $\mathrm{ng} / \mathrm{ml})$ or ETVAX WCC (200-200,000 bacteria/ml) alone or in combination with $\mathrm{dmLT}(10 \mu \mathrm{g} / \mathrm{ml})$, where after culture supernatants were collected. PBMCs were also stimulated with $\mathrm{dmLT}$ alone for 18 hours at increasing concentrations $(1-50 \mu \mathrm{g} / \mathrm{ml})$. All supernatants were stored at $-70^{\circ} \mathrm{C}$ before cytokine analysis.

\section{Analysis of Cytokines}

The concentrations of IL-1 $\beta$ (from $18 \mathrm{~h}$ culture supernatants), and IL-17A and IFN- $\gamma$ (from $72 \mathrm{~h}$ culture supernatants), were determined using sandwich ELISA (eBioscience, USA), following the manufacturers' instructions. The concentrations of IL-6, IL-23, IL-12p70, IL-10 and TFN- $\alpha$ (from $18 \mathrm{~h}$ culture supernatants) were determined using a multiplex electrochemiluminescence assay (Vplex, Meso Scale Discovery, USA).

\section{Statistical Analyses}

Cytokine responses were evaluated using the Friedman test with Dunn's multiple comparison post test, the Wilcoxon signed rank test or Mann-Whitney test, as applicable. $P$-values $<0.05$ were considered as significant. All statistical analyses were performed with GraphPad Prism (Graph Pad Software, USA) version 6.0.

\section{RESULTS}

\section{Effect of dmLT on IL-17A and IFN- $\gamma$ Production}

To study the influence of dmLT on T cell responses in cells from infants versus adults, PBMCs collected from the two different age groups were stimulated with $\mathrm{dmLT}$ in combination with the superantigen SEB or the mitogen PHA. Cells were stimulated polyclonally with SEB and PHA rather than with purified antigens to allow analysis of the adjuvant effect in all participants in a consistent manner, with limited influence of the infection or vaccination history of the individual. The adjuvant effect was evaluated by analyzing levels of IL-17A and IFN- $\gamma$ in culture supernatants by ELISA after $72 \mathrm{~h}$ of stimulation. In cells from both adults and infants, SEB or PHA stimulation alone induced IL-17A responses, but the magnitudes of responses were lower in infants compared to adults (Figures 1A, B). In contrast, stimulation with dmLT alone did not induce any detectable IL-17A production at any concentration tested (1$10 \mu \mathrm{g} / \mathrm{ml}$; Figures 1A, B).

Stimulation of cells with SEB in combination with increasing concentrations of dmLT, resulted in significantly enhanced IL17A production compared to stimulation with SEB alone in cells from both adults and infants (Figures 1A, B). In adults, the production of IL-17A increased significantly in the presence of the lowest $\mathrm{dmLT}$ concentration tested $(1 \mu \mathrm{g} / \mathrm{ml}, 2.1$-fold mean increase compared to SEB alone) and addition of $10 \mu \mathrm{g} / \mathrm{ml}$ resulted in even higher IL-17A production (2.7-fold mean increase) (Figure 1A). PBMCs from adults also showed significantly increased IL-17A production when $10 \mu \mathrm{g} / \mathrm{ml}$ of dmLT was added in combination with PHA, and a trend for 
A

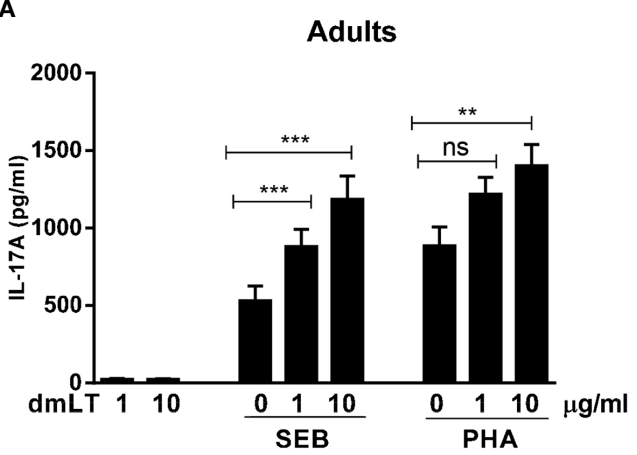

C

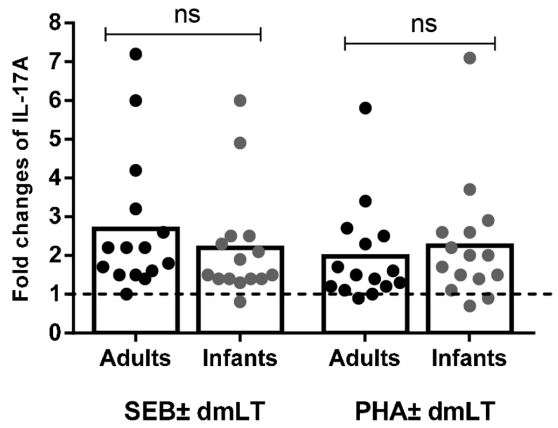

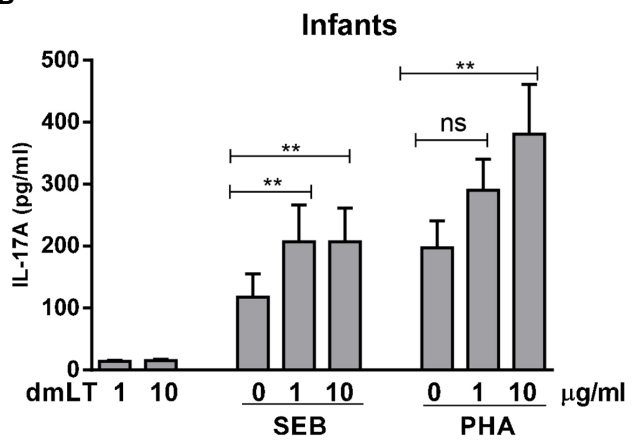

D

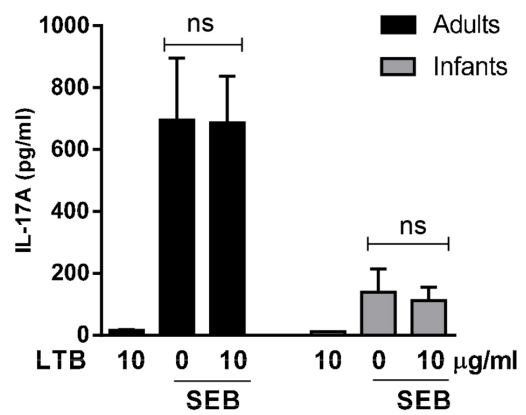

FIGURE 1 | Effect of dmLT and LTB on IL-17A responses induced by SEB and PHA stimulation in PBMCs from adults and infants. IL-17A concentrations in cultures with cells from $(\mathbf{A})$ adults $(n=15)$ and $(\mathbf{B})$ infants $(n=15)$ stimulated with increasing concentrations of $\mathrm{dmLT}$ alone $(1 \mathrm{or} 10 \mu \mathrm{g} / \mathrm{ml})$ or with $\mathrm{SEB}$ or PHA. (C) Fold changes in IL-17A concentrations in cultures with PBMCs from adults and infants stimulated with SEB or PHA plus dmLT (10 $\mu \mathrm{g} / \mathrm{ml}$ ) versus SEB or PHA stimulation alone. Bars represent means of fold-change differences and each symbol represents data from one participant. The dashed line indicates no enhancement (fold rise = 1). (D) Effect of LTB $(10 \mu \mathrm{g} / \mathrm{ml}$ ) on IL-17A responses induced by SEB in PBMCs from adults $(\mathrm{n}=7)$ and infants $(\mathrm{n}=7)$ ). (A, B, D) Bars represent mean with SEM of IL-17A concentrations in culture supernatants. Statistical analysis was performed using the Friedman test with Dunn's multiple comparison post-test (A, B), Mann-Whitney test (C) or Wilcoxon matched pairs sign rank test (D) ${ }^{\star \star} P<0.01$, ${ }^{\star \star \star} P<0.001$, ns, not significant; $P>0.05$.

increased production was also observed at $1 \mu \mathrm{g} / \mathrm{ml} \mathrm{dmLT}$ (Figure 1A).

In PBMCs from infants, significant IL-17A enhancing effects of dmLT were also observed when increasing concentrations of $\operatorname{dmLT}(1$ and $10 \mu \mathrm{g} / \mathrm{ml}$ ) were added to the cultures stimulated with SEB (Figure 1B). However, in contrast to adults, the two dmLT concentrations induced comparable IL-17A production. Similar to adults, dmLT $10 \mu \mathrm{g} / \mathrm{ml}$ caused significant IL-17A enhancement when combined with PHA stimulation in PBMCs from infants with a trend for increased responses seen already at $1 \mu \mathrm{g} / \mathrm{ml}$ (Figure 1B).

Since the levels of IL-17A production in response to PHA and SEB alone differed between cells from infants and adults, we also evaluated if the relative capacity of dmLT to enhance responses differed between infants and adults after normalization of the IL$17 \mathrm{~A}$ levels induced by SEB or PHA stimulation alone. The relative increase (fold-rise) in IL-17A production in cells stimulated with $10 \mu \mathrm{g} / \mathrm{ml} \mathrm{dmLT}$ compared to stimuli alone without dmLT were comparable in both age groups (Figure
1C, adults vs. infants mean fold rises: SEB 2.7 versus 2.2; PHA 2.0 versus 2.3), supporting that dmLT has a comparable adjuvant effect on $\mathrm{T}$ cell responses in the two age groups.

In contrast to the clear adjuvant effect observed when dmLT was added to the cultures, addition of $10 \mu \mathrm{g} / \mathrm{ml}$ of LTB, which spontaneously forms pentamers, but lack the enzymatically active A subunit, did not affect IL-17A responses to SEB in either adult or infant cells (Figure 1D). Responses to LTB alone were also very low.

SEB and PHA also induced strong IFN $-\gamma$ responses, with higher magnitudes of responses in PBMCs from adults compared to infants (Figures 2A, B). However, dmLT (Figures 2A, B) or LTB (Supplementary Figure 1) did not induce any IFN- $\gamma$ production when added alone and did not enhance IFN- $\gamma$ production in response to SEB or PHA in cells from either adults or infants.

Collectively, these results show that dmLT, in contrast to LTB, has a clear adjuvant effect on IL-17A responses in cells from both infants and adults, whereas no adjuvant effect was observed on IFN $-\gamma$ responses in either of the age groups. 
A

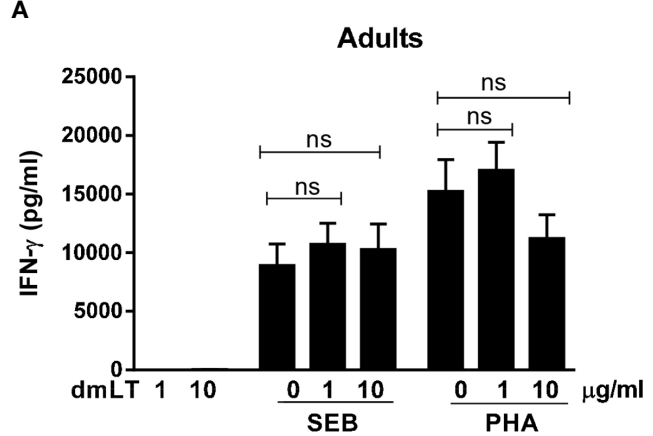

B

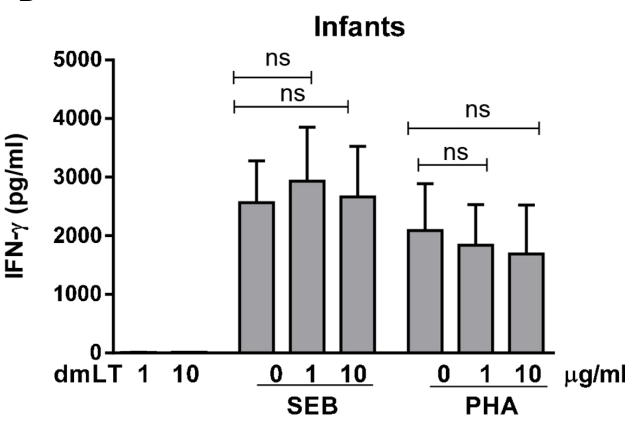

FIGURE 2 | Effect of dmLT on IFN- $\gamma$ responses induced by SEB and PHA stimulation in PBMCs from adults and infants. IFN- $\gamma$ concentrations in cultures with cells from $(\mathbf{A})$ adults $(n=15)$ and $(\mathbf{B})$ infants $(n=15)$ stimulated with increasing concentrations of $\mathrm{dmLT}$ alone $(1 \mathrm{or} 10 \mu \mathrm{g} / \mathrm{ml})$ or with SEB or PHA. Bars represent mean with SEM of IFN- $\gamma$ concentrations in culture supernatants. Statistical analysis was performed using the Friedman test with Dunn's multiple comparison post-test. ns, not significant; $P>0.05$.

\section{Role of IL-1 $\beta$ in Promotion of IL-17A Responses}

To evaluate the role of IL-1 $\beta$ in mediating the dmLT adjuvant effect in adult and infant PBMCs, IL-1RA was added to cell cultures to prevent downstream effects of IL-1 $\beta$ by blocking the IL-1 receptor. Addition of IL-1RA to cells stimulated with SEB plus dmLT decreased the IL-17A production to levels corresponding to those measured in cultures stimulated with SEB alone in cells from all tested adults and infants (Figure 3). These results support an important role for IL-1 $\beta$ in the adjuvant effect of dmLT in both infants and adults.

\section{IL-1 $\beta$ Responses to dmLT, ETVAX WCC and LPS}

To further investigate if $\mathrm{dmLT}$ alone could induce production of IL- $1 \beta$ in PBMCs from both adults and infants, PBMCs were stimulated with increasing concentrations of $\operatorname{dmLT}(1,10,20$ and $50 \mu \mathrm{g} / \mathrm{ml}$ ) for 18 hours, a time point when mainly innate cells respond to stimulation. dmLT alone activated PBMCs from both infants and adults to produce IL- $1 \beta$ in a dose-dependent manner (Figure 4A). The levels of IL-1 $\beta$ were comparable in adults and infants at all dmLT concentrations tested $(P>0.05)$. Increased IL$1 \beta$ production ( $\geq 2$-fold increase compared to stimulation with medium alone) was already seen at the concentration of $10 \mu \mathrm{g} / \mathrm{ml}$ of dmLT in PBMCs from $56 \%$ of infants and $40 \%$ of adults. However, even stronger and more consistent IL-1 $\beta$ responses were observed at $50 \mu \mathrm{g} / \mathrm{ml} \mathrm{dmLT} \mathrm{in} \mathrm{cells} \mathrm{from} \mathrm{both} \mathrm{adults}(90 \%$, 6.8 mean fold-rise) and infants $(67 \%, 4.1$ mean fold-rise, $P>0.05$, adults versus infants). Control experiments showed that stimulation with LTB induced little IL-1 $\beta$ production (data not shown).

Since dmLT has been shown to enhance immune responses to the inactivated ETEC vaccine ETVAX in several studies $(12,13$,
A

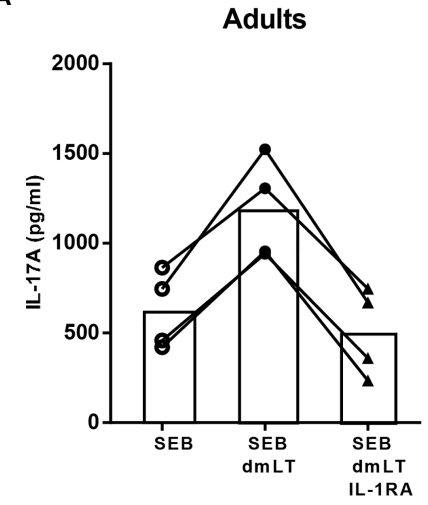

B

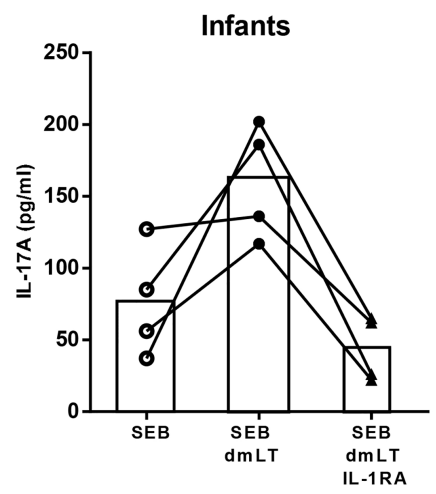

FIGURE 3 | Role of IL-1 signaling in dmLT-induced promotion of IL-17A responses. IL-17A concentrations in cultures with PBMCs from (A) adults ( $\mathrm{n}=4$ ) and (B) infants $(\mathrm{n}=4)$ stimulated with SEB alone or SEB $+10 \mu \mathrm{g} / \mathrm{mL}$ dmLT with or without addition of IL-1 receptor antagonist (IL-1RA). Each symbol and line represents data from one participant. 
A

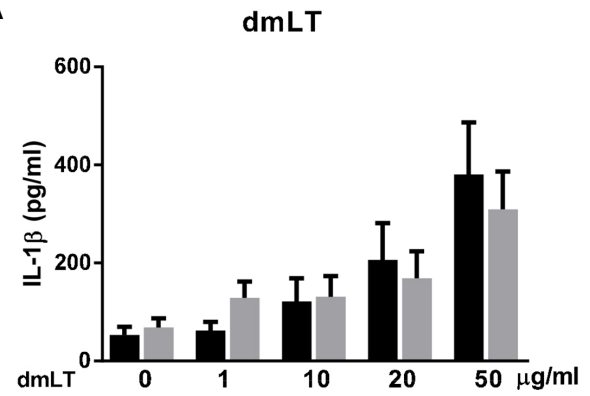

B

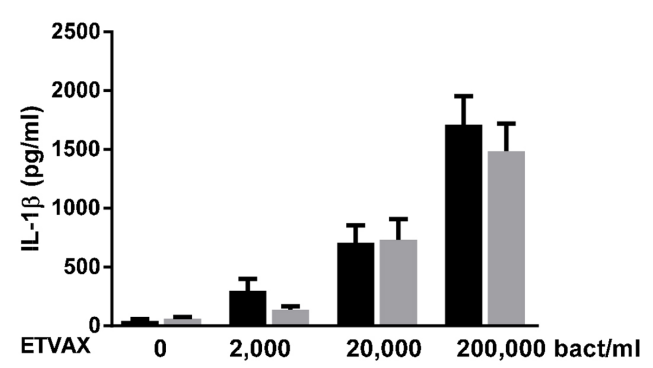

C

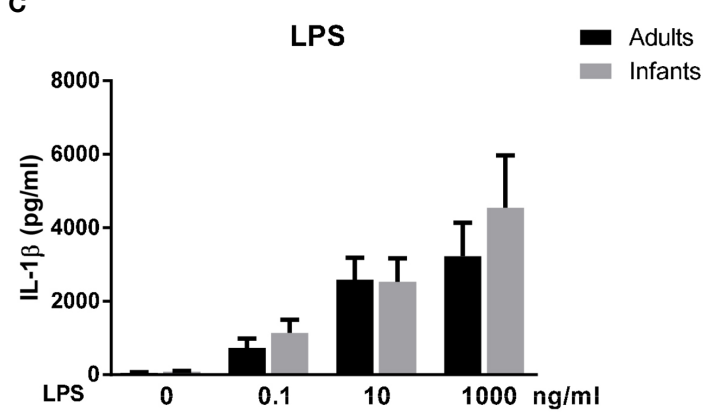

FIGURE 4 | IL-1 $\beta$ production from PBMCs from adults and infants stimulated with dmLT or ETVAX WCC. IL-1 $\beta$ concentrations in cultures with cells from PBMCs from adults and infants with increasing concentrations of (A) dmLT (1-50 $\mathrm{gg} / \mathrm{ml}$, adults; $\mathrm{n}=10$, infants; $\mathrm{n}=8)$, (B) ETVAX WCC $(2000-200,000$ bacteria/ml, adults; $n=13$, infants; $n=13$ ) or (C) ETEC O78 LPS (0.1-1000 $\mathrm{ng} / \mathrm{ml}$, adults; $n=9$, infants; $n=8)$. Bars represent means with SEM of concentrations of IL-1 $\beta$ in culture supernatants. $P>0.05$ for comparisons of IL-1 $\beta$ concentrations in cultures with cells from adults versus infants at all stimuli concentrations tested (Mann-Whitney test).

16), we also investigated the role of IL-1 $\beta$ in responses to the bacterial component of ETVAX (whole cell component; WCC), which did not contain any LCTBA or dmLT. In both adult and infant cell cultures, stimulation with ETVAX WCC induced strong and dose-dependent IL-1 $\beta$ responses with comparable levels of IL-1 $\beta$ in the two age groups at all concentrations tested $(P>0.05$, Figure 4B). The IL-1 $\beta$ responses may at least partly be a result of stimulation by the LPS component of the WCC. To investigate if purified LPS also induced IL- $\beta$ production, cells were stimulated with increasing concentrations of purified ETEC O78 LPS (0.1-100 ng/ml), expressed by three of the four E. coli strains in the ETVAX WCC and purified in-house. Strong dosedependent IL-1 $\beta$ production was observed with similar levels produced in cells from infants and adults (Figure 4C). Comparable IL- $1 \beta$ responses were also observed in response to stimulation with commercially available E. coli O111:B4 LPS in both age groups (Supplementary Figure 2).

Depletion of $\mathrm{CD}_{14}{ }^{+}$monocytes from PBMCs isolated from both adults and infants resulted in almost complete loss of IL-1 $\beta$ production in response to stimulation with dmLT, ETVAX WCC or E. coli LPS (Figure 5).

Collectively, these results demonstrate that dmLT alone, as well as ETVAX WCC and E. coli LPS, induce dose-dependent IL$1 \beta$ responses of comparable magnitudes in PBMCs from infants and adults, and suggest that IL-1 $\beta$ was mainly produced by monocytes in both age groups.

\section{IL-1 $\beta$ Production in PBMCs Stimulated With ETVAX WCC or LPS $\pm \mathrm{dmLT}$}

To determine if dmLT can further enhance IL-1 $\beta$ responses induced by ETVAX WCC in PBMCs from adults and infants, IL$1 \beta$ responses were measured after addition of $10 \mu \mathrm{g} / \mathrm{ml}$ of dmLT with different doses of ETVAX WCC (200-200 000 bacteria/ml). In cells from adults, dmLT only enhanced responses to the lowest WCC concentration tested (200 bacteria/ml, Figure 6A). In contrast, in infant cells dmLT enhanced IL- $1 \beta$ responses to both 200 and 2000 bacteria/ml (Figure 6B). dmLT did not influence IL-1 $\beta$ responses to higher doses of ETVAX WCC (20 $000 \mathrm{bacteria} / \mathrm{ml}$, Figures 6A, B, or $200000 \mathrm{bacteria} / \mathrm{ml}$, data not shown).

Next, we tested whether dmLT may also influence IL-1 $\beta$ responses to purified LPS. PBMCs were stimulated with increasing concentrations of ETEC O78 LPS $(0.01-1 \mathrm{ng} / \mathrm{ml})$ alone and in combination with $10 \mu \mathrm{g} / \mathrm{ml}$ of dmLT. In cells from both adults and infants, significantly enhanced IL-1 $\beta$ responses were observed only when dmLT was added with the lowest tested concentration of O78 LPS $(0.01 \mathrm{ng} / \mathrm{ml})$ compared to LPS alone (Figures 6C, D). 

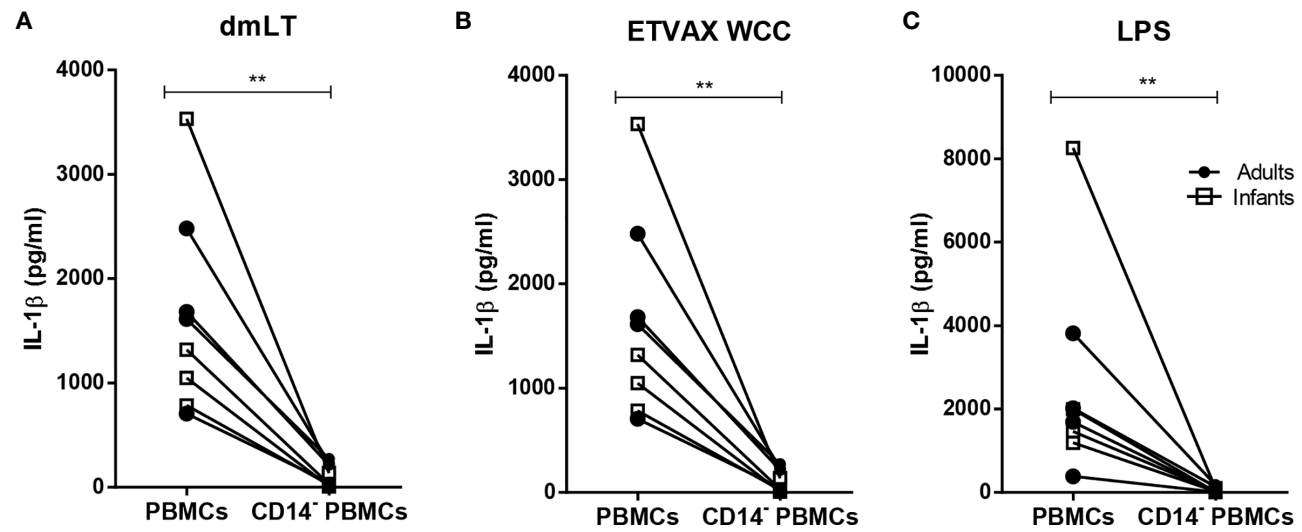

FIGURE 5 | IL-1 $\beta$ production from PBMCs depleted of CD14+ monocytes in response to dmLT, ETVAX WCC and LPS. IL-1 $\beta$ concentrations in cultures with PBMCs and PBMCs depleted of CD14 ${ }^{+}$monocytes from adults ( $n=4$, closed symbols) and infants ( $n=5$, open symbols) stimulated with (A) dmLT (20 $\left.\mu \mathrm{g} / \mathrm{ml}\right)$, (B) ETVAX WCC (200,000 bacteria/ml) or (C) E. coli. O111:B4 LPS (10 ng/ml). Each symbol and line represent data from one participant. Statistical analysis was performed using the Wilcoxon matched-pairs signed rank test. ${ }^{\star *} P<0.01$.

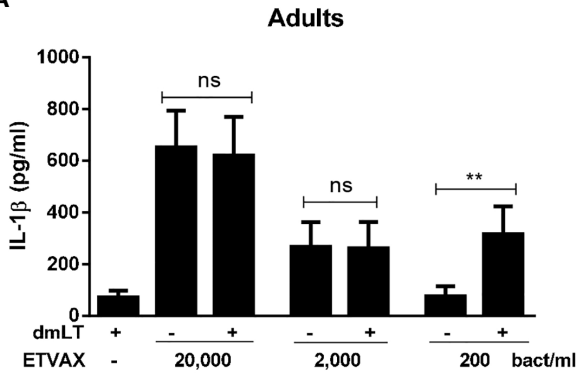

C

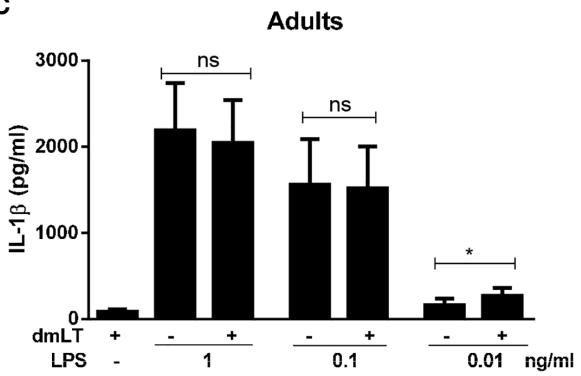

B

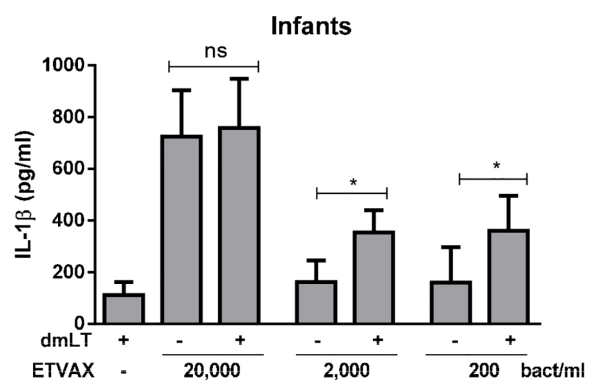

D

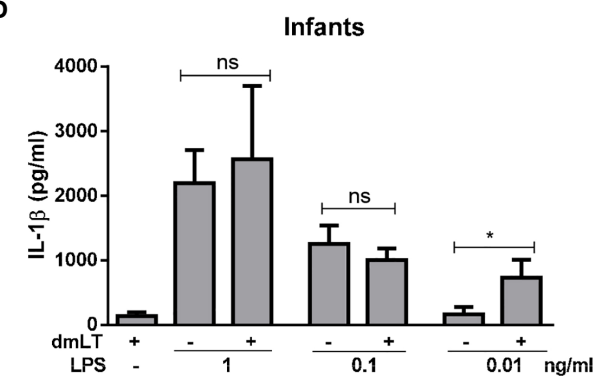

FIGURE 6 | IL-1 $\beta$ production from PBMCs stimulated with ETVAX WCC or LPS \pm dmLT. IL-1 $\beta$ concentrations in cultures with PBMCs from (A, C) adults and (B, D) infants stimulated with increasing concentrations of ETVAX WCC (200-20,000 bacteria/ml) or ETEC O78 LPS $(0.01-1 \mathrm{ng} / \mathrm{ml})$ alone or with $10 \mu \mathrm{g} / \mathrm{ml} \mathrm{dmLT}$. Bars represent mean with SEM of IL-1 $\beta$ concentrations in culture supernatants (ETEC WCC 2000 bacteria/ml; adults $n=13$, infants $n=14,200$ bacteria/ml; adults $n=9$, infants $n=9$, LPS $0.1 \mathrm{ng} / \mathrm{ml}$; adults $n=12$, infants $n=11$, LPS $0.01 \mathrm{ng} / \mathrm{ml}$; adults $n=6$, infants $n=6$ ). Statistical analysis was performed with the Wilcoxon matched-pairs signed rank test. ${ }^{*} P<0.05,{ }^{\star *} P<0.01$, ns, not significant; $P>0.05$.

These results suggest that $\mathrm{dmLT}$ can enhance IL- $1 \beta$ responses induced by very low doses of inactivated E. coli bacteria, as shown by responses to ETVAX WCC, as well as to low concentrations of purified E. coli LPS. Our results also indicate that the adjuvant effect may be apparent over a wider dose-range of bacteria in PBMCs from infants compared to adults.

\section{Expanded Analysis of Cytokines Induced by dmLT and ETVAX WCC}

To determine if dmLT and ETVAX induces additional early cytokine responses, which may modulate Th17 and Th1 and other adaptive immune responses, concentrations of IL-6, IL-23, 
IL-12p70, IL-10 and TNF- $\alpha$ were analyzed in a subset of samples collected after $18 \mathrm{~h}$ of stimulation. For this multiplex analysis, only individuals with a clear dose-dependent increase in IL-1 $\beta$ production in response to dmLT and ETVAX were included (adults $n=5$, infants $n=5$ ).

We found that dmLT induced high production of IL-6 and lower production of IL-23, IL-12p70 and IL-10 (Figures 7A-D) in parallel to the IL- $1 \beta$ responses, in cells from both adults and infants (IL-1 $\beta$ responses in the selected sample subset are shown in Supplementary Figure 3A). A majority of adults and infants responded with increased production of IL-6, IL-23, IL-12p70 and IL-10 when stimulated with $10 \mu \mathrm{g} / \mathrm{ml} \mathrm{dmLT} \mathrm{compared} \mathrm{to}$ levels detected in unstimulated cultures, with even stronger responses observed at $50 \mu \mathrm{g} / \mathrm{ml}$ in most participants. dmLT stimulation did not induce any consistent TNF- $\alpha$ responses in either infant or adult cells (Figure 7E).

Stimulation with ETVAX WCC induced strong, dosedependent IL- 6 and TNF- $\alpha$ responses in both age groups (Figures 8A, E). IL-23, IL-12p70 and IL-10 responses were lower and mainly detected at higher concentrations of bacterial stimuli (Figures 8B-D).

No clear differences in cytokine responses between cells from adults and infants were observed, although infant cells tended to produce more IL-23 in response to the highest tested concentration of ETVAX WCC (Figure 8B).

Finally, we investigated if the addition of dmLT could provide a broad enhancement of cytokine responses induced by ETVAX WCC or O78 LPS. In this subset analysis, only subjects who

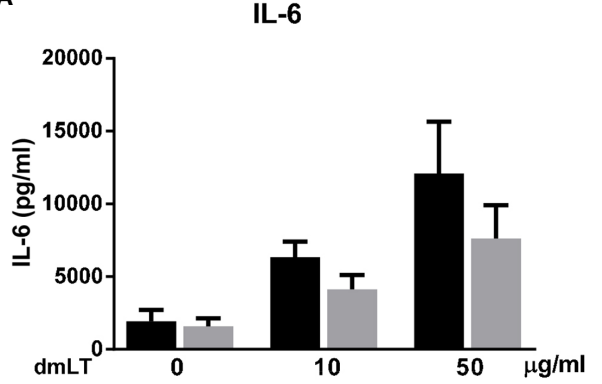

C

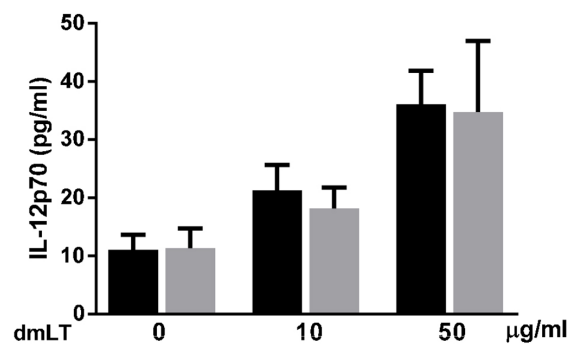

B

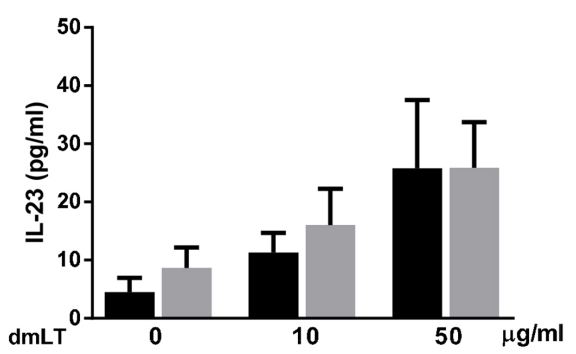

D

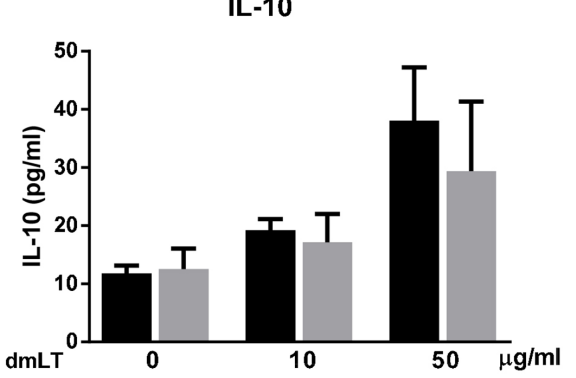

E

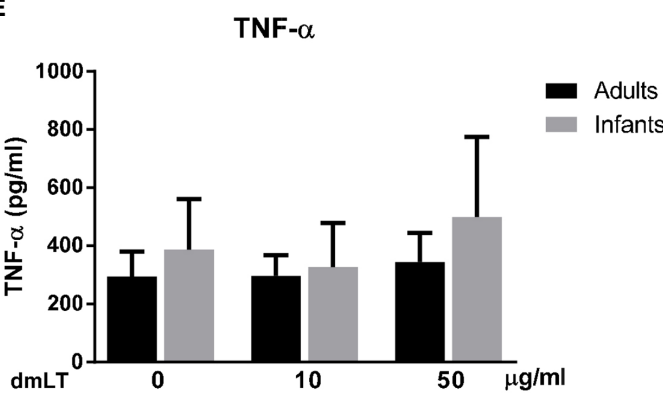

FIGURE 7 | Production of IL-6, IL-23, IL-12p70, IL-10 and TNF- $\alpha$ from PBMCs stimulated with dmLT. Cytokine concentrations in cultures with PBMCs from adults $(n=5)$ and infants $(n=5)$ stimulated with increasing concentrations of $\mathrm{dmLT}(10$ and $50 \mu \mathrm{g} / \mathrm{ml})$. Bars represent mean with SEM of concentrations of (A) IL-6, (B) IL23, (C) IL-12p70, (D) IL-10 and (E) TNF- $\alpha$ in culture supernatants. 
A

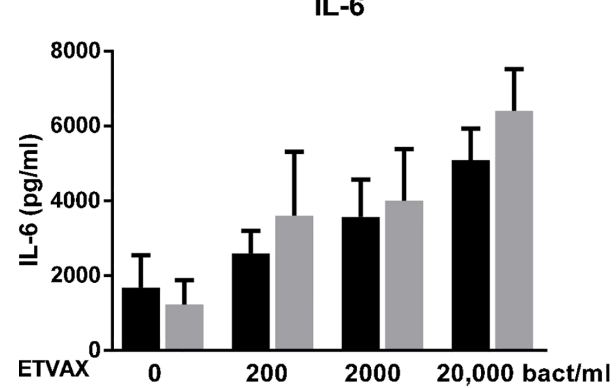

C

IL-12p70

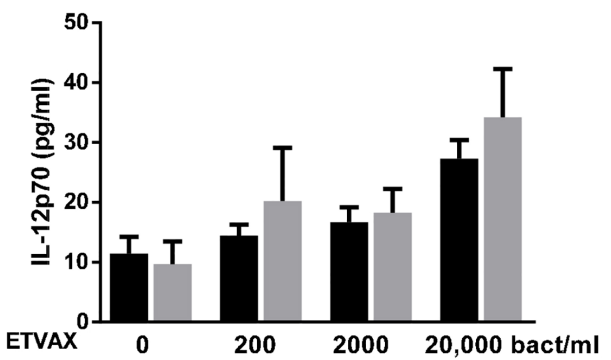

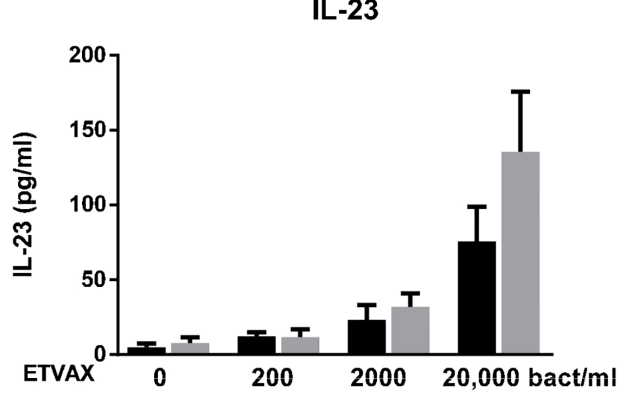

D

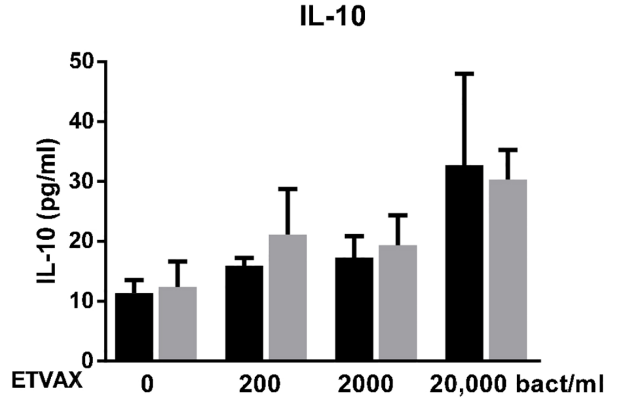

$\mathbf{E}$

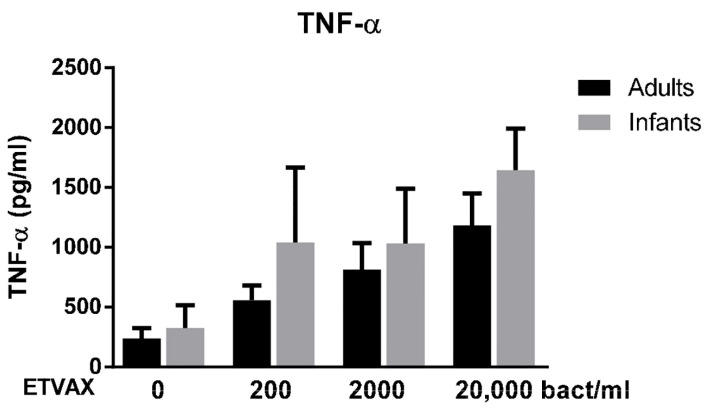

FIGURE 8 | Production of IL-6, IL-23, IL-12p70, IL-10 and TNF- $\alpha$ from PBMCs stimulated with ETVAX WCC. Cytokine concentrations in cultures with PBMCs from adults $(n=5)$ and infants $(n=5)$ stimulated with increasing concentrations of ETVAX WCC (200-20 000 bacteria/ml). Bars represent mean with SEM of concentrations of (A) IL-6, (B) IL-23, (C) IL-12p70, (D) IL-10 and (E) TNF- $\alpha$ in culture supernatants.

responded with $\geq 2$-fold increase in IL- $1 \beta$ production to $10 \mu \mathrm{g} / \mathrm{ml}$ dmLT compared to IL-1 $\beta$ levels produced by unstimulated cells were included (adults $n=5$, infants $n=5$ ). IL- 6 responses to low concentrations of both ETVAX WCC and LPS were increased by the addition of dmLT, but only to the extent expected by adding the responses to dmLT and ETVAX/LPS together in most subjects (Figures 9A, B). In contrast, dmLT appeared to enhance IL-23 responses to both ETVAX WCC and LPS beyond that expected by of a mere additive effect of combining the two stimuli (Figures 9C, D). This is similar to the enhancing effect observed for IL-1 $\beta$ (Figure 6 and Supplementary Figures 3C, D). The trend for enhanced IL-23 responses with dmLT was particularly pronounced in infant cells. dmLT also tended to enhance IL-12p70 responses to ETVAX WCC in infants, but not in adults, and no enhancement was observed for LPS responses (Figures 9E, F). Consistent enhancement beyond an additive effect was not seen for IL-10 or TNF- $\alpha$ for either ETVAX WCC or LPS (Supplementary Figures 4A, B). dmLT tended to decrease TNF- $\alpha$ responses to both ETVAX WCC and LPS (Supplementary Figures 4C, D).

Results from control experiments, where responses in PBMCs depleted of CD14+ monocytes were compared with responses of the original PBMC population, suggested that the IL-6, IL-23, IL12 p70, IL-10 and TNF- $\alpha$ measured after stimulation with dmLT, ETVAX WCC or LPS were derived from monocytes (Supplementary Figure 5).

The results indicate that dmLT and ETVAX WCC alone and together can induce production of a range of cytokines from 
A

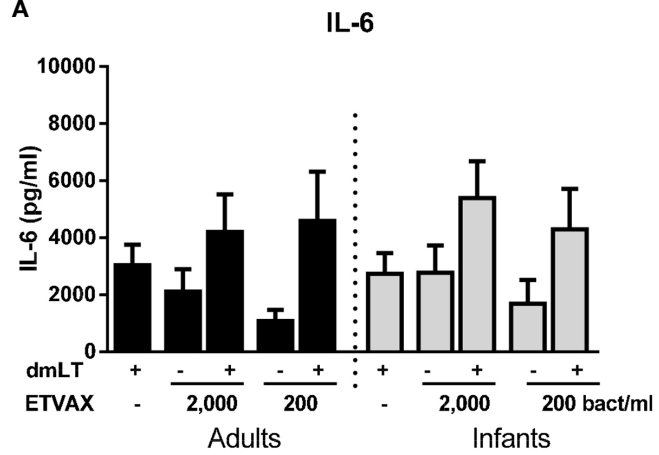

C

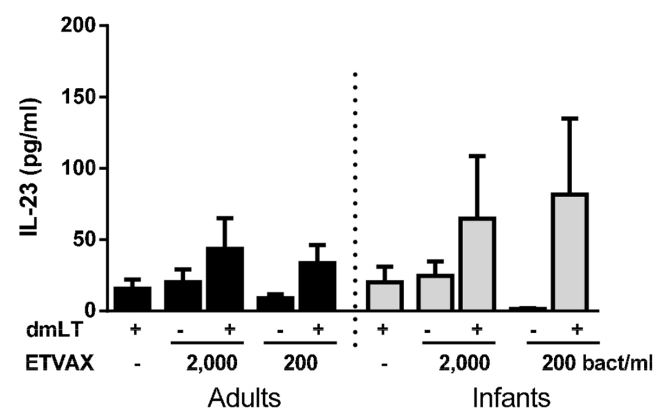

E

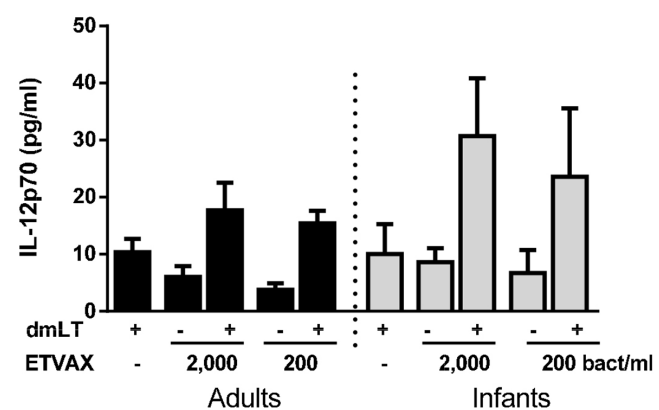

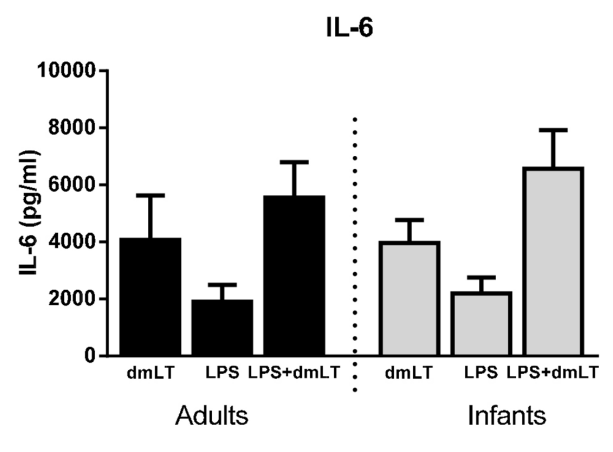

IL-23

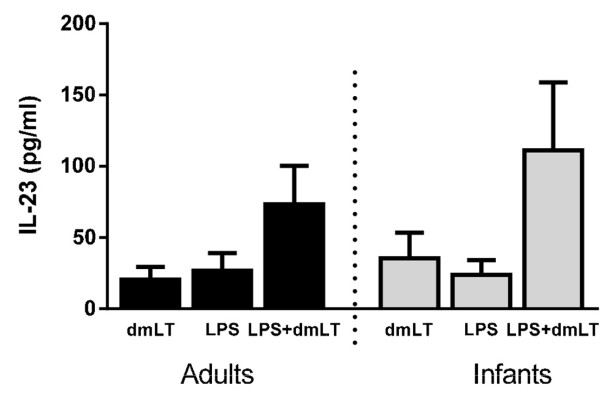

IL-12p70

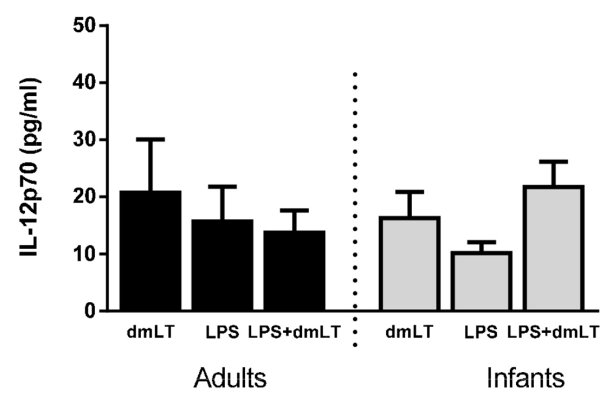

FIGURE 9 | Production of IL-6, IL-23 and IL-12p70 from PBMCs stimulated with ETVAX WCC \pm dmLT. (A, B) IL-6, (C, D) IL-23 and (E, F) IL-12p70 concentrations in cultures with PBMCs from adults $(n=5)$ and infants $(n=5)$ stimulated with ETVAX WCC (200 or 2000 bacteria/ml) or ETEC O78LPS $(0.01$ ng/ml) alone or with 10 $\mu \mathrm{g} / \mathrm{ml} \mathrm{dmLT}$. Bars represent mean with SEM of cytokine concentrations in culture supernatants.

monocytes, which may have broad modulatory effects on adaptive immune responses in both adults and infants.

\section{DISCUSSION}

The mucosal adjuvant dmLT is one of the most well studied nontoxic substances safe for oral administration and can induce and promote multidimensional immune responses to co-delivered antigens (7). Most studies of dmLT and related adjuvants have been performed in mice in vivo, or in vitro using cell lines or cultured mouse cells, and only few studies have been done using human cells (7). In this study, we showed for the first time that PBMCs from infants and adults had similar capacity to be modulated by dmLT in vitro. dmLT promoted IL-17A production from PBMCs isolated from both infants and adults stimulated with SEB or PHA. In addition, our results showed that $\mathrm{dmLT}$ induced strong and comparable dose-dependent IL-1 $\beta$ responses in cells from adults and infants, and that the IL-17A promoting effect was at least partially mediated by IL-1 $\beta$ in both age-groups.

Although dmLT enhanced IL-17A responses in PBMCs from both adults and infants, responses to PHA and SEB were of lower magnitude in cells obtained from infants compared to adults. 
Previous studies using cells from Swedish adults clearly demonstrated that IL-17A was primarily produced by CD4+ T cells after stimulation with PHA and SEB with or without dmLT $(18,19)$. Since IL-17A is produced mainly by memory T cells $(31$, 32), the lower IL-17A production in infants is likely partly due to lower frequencies of memory CD4+ $\mathrm{T}$ cells present in infant compared to adult PBMCs, as previously demonstrated in participants from the same study area (29). The dose-response effect of dmLT was also more pronounced in response to PHA than SEB in infant cells. Previous studies have shown age-related differences in how CD4+ T cells respond to $\operatorname{SEB}(33,34)$, whereas infant $\mathrm{T}$ cells responded to $\mathrm{PHA}$ with comparable proliferation compared to adult cells (35), suggesting that PHA may provide a more robust in vitro stimulation system when comparing responses in different age groups. Importantly, when the relative increase (fold-rises) in IL-17A production were analyzed in cells stimulated with PHA or SEB plus dmLT compared to polyclonal stimulation alone, a comparable relative enhancement of IL-17A responses was observed in both infants and adults and for both types of stimuli. These results suggest that cells from infants have a similar functional capacity as adult cells to be stimulated by dmLT.

Enhanced IL-17A responses may have important downstream consequences on mucosal immune responses. One important function of IL-17A appears to be the clearance of extracellular pathogens during infections by promoting the upregulation of poly Ig receptor on the epithelial cells, thus increasing IgA secretion in the lumen (20). IL-17A is also required for IgA and IgG antibody production, as demonstrated by a significant impairment of mucosal IgA and systemic IgA and IgG1 production after oral immunization of IL-17A deficient mice (36). Moreover, IL-17A can promote fibroblasts and epithelial cells to secrete pro-inflammatory mediators, including G-CSF, GM-CSF, and IL-8, which increase the production and release of neutrophils from the bone marrow and tissue recruitment $(37,38)$. IL-17A can also induce monocyte migration to tissues both directly and via induction of chemokines such as CCL2 (39). By promoting IL-17A production, dmLT may thus enhance both innate immunity and humoral responses, which may increase the protection against mucosal infections.

We also showed that LTB, in contrast to dmLT, did not affect IL-17A responses in cells from either infants or adults. This is consistent with our previous demonstration that both CTB and LTB lack adjuvant activity in cells from adult Swedes $(18,19)$ and with previous in vitro and in vivo studies showing reduced or completely blocked immunological effects using LTB or LT variants with mutations in critical positions in the A subunit (7).

Our results showed considerably lower IL-17A responses after the addition of IL-1 receptor antagonist in PBMC cultures stimulated with SEB plus dmLT, demonstrating the importance of IL-1 $\beta$ in mediating dmLT adjuvant function. The role of IL-1 $\beta$ was also evident from earlier experiments showing that inhibition of the molecules involved in IL-1 $\beta$ production from APCs, e.g. protein kinase A and caspase 1, caused significantly diminished adjuvant effect of dmLT (19). Several studies have demonstrated the potential role of IL-1 $\beta$, in combination with IL-6 and/or IL-23, for the differentiation of human Th17 cells from naïve T cells, as well as promotion of IL17A production from already differentiated Th17 memory $\mathrm{T}$ cells $(40,41)$. APCs, mostly monocytes and DCs, play major role in Th17 differentiation by producing IL-1 $\beta$, IL-23 and IL-6 (40, 42, 43). In our study, we also showed that PBMCs from infants produced IL-1 $\beta$ at levels similar to adults at all concentrations of dmLT tested $(1-50 \mu \mathrm{g} / \mathrm{ml})$. We further showed that stimulation with ETVAX or LPS alone induced strong dose-dependent IL-1 $\beta$ production of comparable magnitudes in PBMCs from both adults and children. Depletion experiments verified that most of the IL-1 $\beta$ detected in the supernatants after stimulation with dmLT, ETVAX or LPS was derived from monocytes. Our previous studies have demonstrated similar proportions of CD14+ monocytes in PBMCs isolated from infants and adults from the same study area (29), suggesting that monocytes from infants and adults have comparable ability to respond to the stimuli tested.

A key finding in this study was the ability of dmLT to enhance IL- $1 \beta$ responses to ETVAX whole cell component and purified $E$. coli LPS in both age groups. However, the enhancement was only observed at very low stimuli concentrations. Thus, it is clear that LPS, and potentially other bacterial components of the vaccine, have a potent capacity to induce IL- $1 \beta$ production on their own, but when the stimuli concentrations were reduced, dmLT could achieve an adjuvant effect. The adjuvant effect was also apparent over a wider dose-range of bacteria when stimulating cells from infants compared to from adults. Although the adjuvant effect was only observed at very low concentrations of bacteria and LPS, which are difficult to directly translate into in vivo conditions, this is an interesting observation, particularly since fractionated doses of ETVAX are given to children in order to avoid side effects such as vomiting. The amount of vaccine reaching individual immune cells in the mucosa is likely to be low, supporting the relevance of our in vitro findings. Consistent with these in vitro results, co-administration of dmLT with fractionated ETVAX doses was recently shown to significantly enhance IgA responses to O78 LPS in Bangladeshi infants (Svennerholm, A-M., unpublished results).

Although our study focused on IL-17A responses and the role of IL-1 $\beta$ for induction of such responses, we also analyzed whether dmLT and ETVAX WCC induced a broader range of cytokines related to Th17, Th1, immunosuppression and inflammation in a subset of samples. We found that dmLT and ETVAX WCC induced production of relatively high concentrations of IL- 6 and lower but consistent production of IL-23. The adjuvant effect of dmLT when added together with ETVAX WCC was particularly pronounced for IL-23 responses in infants. This is interesting, considering the involvement of IL23 in the induction and/or maintenance of Th17 cells $(40,41)$. We have previously shown that neutralization of IL-23, but not IL-6, can partially block the adjuvant effect of dmLT on IL-17A responses in cells from adults in vitro, although the blocking effect of IL-1 neutralization was more complete (18). The relative importance of IL-1 $\beta$ and IL-23 in the adjuvant function of dmLT should be investigated in further detail in continued studies. 
We observed induction of IL-12p70 in response to both dmLT and ETVAX WCC, and a trend for enhanced responses when dmLT was combined with ETVAX WCC in cultures with infant cells. IL-12 is important for induction of Th1 responses and our results support that these responses may also be influenced by dmLT, particularly in infants. However, in contrast to the clear adjuvant effect of dmLT on IL-17A responses to polyclonal T cell stimuli, dmLT had no effect on IFN- $\gamma$ responses, neither in cells from infants nor adults, in our study. These results are consistent with previous findings using cells from Swedish adults, where dmLT strongly supported IL-17A, but not IFN- $\gamma$ responses elicited by stimulation with PHA, SEB, pneumococcal whole cell antigen or mycobacterial purified protein derivative $(18,19)$. However, dmLT has been shown to promote both IL-17A and IFN- $\gamma$ production in response to LTB stimulation of cells derived from Swedish adults immunized with a prototype ETEC vaccine (18). Studies have shown that dmLT can enhance Th1 in vivo responses to some vaccines in mice, although the effect on Th17 responses have been more consistently observed across different studies (7). Thus, the ability of dmLT to affect Th1 responses may vary depending on antigen type, potentially having a greater ability to modulate responses to purified protein antigens such as LTB or tetanus toxoid, than to more complex antigen preparations, which may contain microbial components with intrinsic immunomodulatory properties. Further studies are needed to evaluate the in vitro adjuvant effect of dmLT on Th1 and Th17 responses to purified ETEC antigens, such as colonization factors, in infants. However, due to the limited blood volumes available from infants, and the transient nature of $\mathrm{T}$ cell responses in peripheral blood after mucosal infection or vaccination, such studies are challenging to perform and we did not have access to samples that allowed such analysis in this study.

dmLT and ETVAX WCC at high concentrations also induced IL-10, which has mainly immunosuppressive functions (44). In accordance with previous observations from studies of cholera toxin and LT $(45,46)$, dmLT appeared to suppress rather than enhance TNF- $\alpha$ responses to LPS or ETVAX WCC. Our results thus suggest that dmLT may induce a broad range of cytokines in addition to IL$1 \beta$ from innate cells, but may also suppress the production of other cytokines. It is also clear that ETVAX WCC and E. coli LPS induced broad cytokine responses even in the absence of the adjuvant, and that the effect of dmLT is likely to be strongest at low antigen concentrations. However, as we only analyzed a limited number of cytokines in a relatively small number of samples, additional studies are needed to fully characterize the breadth of cytokine responses induced and modulated by dmLT and ETVAX. Our recent clinical demonstration that dmLT is safe in infants and children, and that dmLT can enhance IgA responses to LPS, are supporting the potential of this adjuvant for infant vaccination (16, and Svennerholm A-M et al, unpublished results). It will be important to further study the dose-response relationship of dmLT in combination with different vaccines both in vitro and in vivo and in different age groups to identify optimal combinations of adjuvant and antigen doses, which induces sufficient proinflammatory cytokines to drive protective responses, but do not cause any adverse or suppressive effects.

Collectively, our results suggest that dmLT can promote both innate and adaptive immune responses in infants. Enhanced production of IL-1 $\beta$ and other cytokines primarily produced by innate cells such as IL-23, may lead to increased IL-17A responses with subsequently enhanced production and secretion of secretory IgA. These responses may help to protect against ETEC and other mucosal infections. The ability of dmLT to enhance cytokine responses to low doses of ETVAX WCC and LPS in infants suggests that dmLT may also be used to overcome hyporesponsiveness to other whole cell- or LPS-based vaccines such as cholera, Salmonella Typhi and Shigella vaccines in infants in low- and middle-income countries. This will be an important target for investigation in future in vitro as well as in vivo studies. Our results thus encourage further evaluation of dmLT as an adjuvant to promote vaccine induced responses in infants.

\section{DATA AVAILABILITY STATEMENT}

The raw data supporting the conclusions of this article will be made available by the authors, without undue reservation.

\section{ETHICS STATEMENT}

The studies involving human participants were reviewed and approved by Ethical review committee of the International Centre for Diarrhoeal Disease Research, Bangladesh. Written informed consent to participate in this study was provided by the participants' legal guardian/next of kin.

\section{AUTHOR CONTRIBUTIONS}

$\mathrm{AL}, \mathrm{MA}, \mathrm{TB}$, and FQ designed and planned the studies. MA, NN, $\mathrm{SB}, \mathrm{LH}$, and SA performed the immunological analyses. MA and AL wrote the manuscript. All authors contributed to the article and approved the submitted version.

\section{FUNDING}

This work was supported by the European Union Seventh Framework Programme (FP7/2007-2013, grant agreement no. 261472 STOPENTERICS), the Swedish Research Council (grant number VR 348-2014-4228) and PATH through its enteric vaccine project. The funders had no role in study design, data collection or analysis, decision to publish, or preparation of the manuscript. icddr,b is thankful to the donors for their support to its research efforts. icddr,b also gratefully acknowledges the following donors who provided unrestricted support: Governments of Bangladesh, Canada, Sweden and the UK.

\section{ACKNOWLEDGMENTS}

We acknowledge the support of the study participants as well as the dedicated field and laboratory workers in this study at icddr, 
b. We also thank Joanna Kaim at the Department of Microbiology and Immunology at the University of Gothenburg for excellent technical assistance and Scandinavian Biopharma, Solna, Sweden, for providing antigens and dmLT used in the study.

\section{REFERENCES}

1. Walker RI. An Assessment of Enterotoxigenic Escherichia Coli and Shigella Vaccine Candidates for Infants and Children. Vaccine (2015) 33(8):954-65. doi: 10.1016/j.vaccine.2014.11.049

2. Das S, Mohakud NK, Suar M, Sahu BR. Vaccine Development for Enteric Bacterial Pathogens: Where do We Stand? Pathog Dis (2018) 76(5):1-14. doi: 10.1093/femspd/fty057

3. Dennehy PH. Rotavirus Vaccines: An Overview. Clin Microbiol Rev (2008) 21 (1):198-208. doi: 10.1128/cmr.00029-07

4. Czerkinsky C, Holmgren J. Vaccines Against Enteric Infections for the Developing World. Philos Trans R Soc Lond B Biol Sci (2015) 370(1671):113. doi: $10.1098 /$ rstb. 2015.0142

5. Leung DT, Uddin T, Xu P, Aktar A, Johnson RA, Rahman MA, et al. Immune Responses to the O-specific Polysaccharide Antigen in Children Who Received a Killed Oral Cholera Vaccine Compared to Responses Following Natural Cholera Infection in Bangladesh. Clin Vaccine Immunol CVI (2013) 20(6):780-8. doi: 10.1128/cvi.00035-13

6. Levine MM. Immunogenicity and Efficacy of Oral Vaccines in Developing Countries: Lessons From a Live Cholera Vaccine. BMC Biol (2010) 8:129. doi: 10.1186/1741-7007-8-129

7. Clements JD, Norton EB. The Mucosal Vaccine Adjuvant LT(R192G/L211A) or Dmlt. mSphere (2018) 3(4):e00215-18. doi: 10.1128/mSphere.00215-18

8. Norton EB, Lawson LB, Freytag LC, Clements JD. Characterization of a Mutant Escherichia Coli Heat-Labile Toxin, LT(R192G/L211A), as a Safe and Effective Oral Adjuvant. Clin Vaccine Immunol CVI (2011) 18(4):546-51. doi: 10.1128/CVI.00538-10

9. Freytag LC, Clements JD. Mucosal Adjuvants. Vaccine (2005) 23(15):180413. doi: 10.1016/j.vaccine.2004.11.010

10. Norton EB, Lawson LB, Mahdi Z, Freytag LC, Clements JD. The A Subunit of Escherichia Coli Heat-Labile Enterotoxin Functions as a Mucosal Adjuvant and Promotes IgG2a, IgA, and Th17 Responses to Vaccine Antigens. Infect Immun (2012) 80(7):2426-35. doi: 10.1128/iai.00181-12

11. Lee S, Picking WL, Tzipori S. The Immune Response of Two Microbial Antigens Delivered Intradermally, Sublingually, or the Combination Thereof. Microbes infect (2014) 16(9):796-803. doi: 10.1016/j.micinf.2014.07.013

12. Holmgren J, Bourgeois L, Carlin N, Clements J, Gustafsson B, Lundgren A, et al. Development and Preclinical Evaluation of Safety and Immunogenicity of an Oral ETEC Vaccine Containing Inactivated E. Coli Bacteria Overexpressing Colonization Factors CFA/I, Cs3, CS5 and CS6 Combined With a Hybrid LT/CT B Subunit Antigen, Administered Alone and Together With dmLT Adjuvant. Vaccine (2013) 31(20):2457-64. doi: 10.1016/ j.vaccine.2013.03.027S0264-410X(13)00337-X[pii

13. Lundgren A, Bourgeois L, Carlin N, Clements J, Gustafsson B, Hartford M, et al. Safety and Immunogenicity of an Improved Oral Inactivated Multivalent Enterotoxigenic Escherichia Coli (ETEC) Vaccine Administered Alone and Together With dmLT Adjuvant in a Double-Blind, Randomized, PlaceboControlled Phase I Study. Vaccine (2014) 32(52):7077-84. doi: 10.1016/ j.vaccine.2014.10.069S0264-410X(14)01459-5[pii

14. Harro C, Louis Bourgeois A, Sack D, Walker R, DeNearing B, Brubaker J, et al. Live Attenuated Enterotoxigenic Escherichia Coli (ETEC) Vaccine WithdmLT Adjuvant Protects Human Volunteers Against Virulent Experimental ETEC Challenge. Vaccine (2019) 37(14):1978-86. doi: 10.1016/j.vaccine.2019.02.025

15. Akhtar M, MI C, TR B, Kaim J, Ahmed T, et al. Evaluation of the Safety and Immunogenicity of the Oral Inactivated Multivalent Enterotoxigenic Escherichia Coli Vaccine ETVAX in Bangladeshi Adults in a Double-Blind, Randomized, Placebo-Controlled Phase I Trial Using Electrochemiluminescence and ELISA Assays for Immunogenicity Analyses. Vaccine (2018) 37:5645-56. doi: 10.1016/ j.vaccine.2018.11.040

\section{SUPPLEMENTARY MATERIAL}

The Supplementary Material for this article can be found online at: https://www.frontiersin.org/articles/10.3389/fimmu.2021. 654872/full\#supplementary-material

16. Qadri F, Akhtar M, Bhuiyan TR, Chowdhury MI, Ahmed T, Rafique TA, et al. Safety and Immunogenicity of the Oral, Inactivated, Enterotoxigenic Escherichia Coli Vaccine ETVAX in Bangladeshi Children and Infants: A Double-Blind, Randomised, Placebo-Controlled Phase 1/2 Trial. Lancet Infect Dis (2019) 20:208-19. doi: 10.1016/S1473-3099(19)30571-7

17. Cheng E, Cardenas-Freytag L, Clements JD. The Role of cAMP in Mucosal Adjuvanticity of Escherichia Coli Heat-Labile Enterotoxin (LT). Vaccine (1999) 18(1-2):38-49. doi: 10.1016/S0264-410X(99)00168-1

18. Leach S, Clements JD, Kaim J, Lundgren A. The Adjuvant Double Mutant Escherichia Coli Heat Labile Toxin Enhances IL-17A Production in Human T Cells Specific for Bacterial Vaccine Antigens. PloS One (2012) 7(12):e51718. doi: 10.1371/journal.pone.0051718

19. Larena M, Holmgren J, Lebens M, Terrinoni M, Lundgren A. Cholera Toxin, and the Related Nontoxic Adjuvants mmCT and dmLT, Promote Human Th17 Responses Via Cyclic AMP-protein Kinase A and InflammasomeDependent IL-1 Signaling. J Immunol (2015) 194(8):3829-39. doi: 10.4049/ jimmunol.1401633

20. Cao AT, Yao S, Gong B, Elson CO, Cong Y. Th17 Cells Upregulate Polymeric Ig Receptor and Intestinal IgA and Contribute to Intestinal Homeostasis. J Immunol (2012) 189(9):4666-73. doi: 10.4049/jimmunol.1200955

21. Mitsdoerffer M, Lee Y, Jager A, Kim HJ, Korn T, Kolls JK, et al. Proinflammatory T Helper Type 17 Cells are Effective B-cell Helpers. Proc Natl Acad Sci USA (2010) 107(32):14292-7. doi: 10.1073/pnas.1009234107

22. Annunziato F, Cosmi L, Santarlasci V, Maggi L, Liotta F, Mazzinghi B, et al. Phenotypic and Functional Features of Human Th17 Cells. J Exp Med (2007) 204(8):1849-61. doi: 10.1084/jem.20070663

23. Tarlinton D. Il-17 Drives Germinal Center B Cells? Nat Immunol (2008) 9 (2):124-6. doi: 10.1038/ni0208-124

24. Hsu HC, Yang P, Wang J, Wu Q, Myers R, Chen J, et al. Interleukin 17Producing $\mathrm{T}$ Helper Cells and Interleukin 17 Orchestrate Autoreactive Germinal Center Development in Autoimmune BXD2 Mice. Nat Immunol (2008) 9(2):166-75. doi: 10.1038/ni1552

25. Georgountzou A, Papadopoulos NG. Postnatal Innate Immune Development: From Birth to Adulthood. Front Immunol (2017) 8:957. doi: 10.3389/ fimmu.2017.00957

26. Decker ML, Grobusch MP, Ritz N. Influence of Age and Other Factors on Cytokine Expression Profiles in Healthy Children-a Systematic Review. Front Pediatr (2017) 5:255. doi: 10.3389/fped.2017.00255

27. Saso A, Kampmann B. Vaccine Responses in Newborns. Semin Immunopathol (2017) 39(6):627-42. doi: 10.1007/s00281-017-0654-9

28. Levy O, Coughlin M, Cronstein BN, Roy RM, Desai A, Wessels MR. The Adenosine System Selectively Inhibits TLR-mediated TNF-Alpha Production in the Human Newborn. J Immunol (2006) 177(3):1956-66. doi: 10.4049/ jimmunol.177.3.1956

29. Bhuiyan TR, Islam MM, Uddin T, Chowdhury MI, Janzon A, Adamsson J, et al. Th1 and Th17 Responses to Helicobacter Pylori in Bangladeshi Infants, Children and Adults. PloS One (2014) 9(4):e93943. doi: 10.1371/ journal.pone.0093943

30. Svennerholm AM, Ahrén C. Immune Protection Against Enterotoxinogenic E. Coli: Search for Synergy Between Antibodies to Enterotoxin and Somatic Antigens. Acta Pathol Microbiol Immunol Scand Section C Immunol (1982) 90 (1):1-6. doi: 10.1111/j.1699-0463.1982.tb01409.x

31. Acosta-Rodriguez EV, Rivino L, Geginat J, Jarrossay D, Gattorno M, Lanzavecchia A, et al. Surface Phenotype and Antigenic Specificity of Human Interleukin 17-Producing T Helper Memory Cells. Nat Immunol (2007) 8(6):639-46. doi: 10.1038/ni1467

32. Lundgren A, Bhuiyan TR, Novak D, Kaim J, Reske A, Lu YJ, et al. Characterization of Th17 Responses to Streptococcus Pneumoniae in Humans: Comparisons Between Adults and Children in a Developed and a 
Developing Country. Vaccine (2012) 30(26):3897-907. doi: 10.1016/ j.vaccine.2012.03.082

33. Rudolph ME, McArthur MA, Barnes RS, Magder LS, Chen WH, Sztein MB. Differences Between Pediatric and Adult T Cell Responses to In Vitro Staphylococcal Enterotoxin B Stimulation. Front Immunol (2018) 9:498. doi: 10.3389/fimmu.2018.00498

34. Hanna-Wakim R, Yasukawa LL, Sung P, Fang M, Sullivan B, Rinki M, et al. Age-Related Increase in the Frequency of CD4(+) T Cells That Produce Interferon-Gamma in Response to Staphylococcal Enterotoxin B During Childhood. J Infect Dis (2009) 200(12):1921-7. doi: 10.1086/648375

35. Reen DJ. Activation and Functional Capacity of Human Neonatal CD4 TCells. Vaccine (1998) 16(14-15):1401-8. doi: 10.1016/S0264-410X(98)00099-1

36. Datta SK, Sabet M, Nguyen KP, Valdez PA, Gonzalez-Navajas JM, Islam S, et al. Mucosal Adjuvant Activity of Cholera Toxin Requires Th17 Cells and Protects Against Inhalation Anthrax. Proc Natl Acad Sci USA (2010) 107 (23):10638-43. doi: 10.1073/pnas.1002348107

37. Korn T, Bettelli E, Oukka M, Kuchroo VK. Il-17 and Th17 Cells. Annu Rev Immunol (2009) 27:485-517. doi: 10.1146/annurev.immunol.021908.132710

38. Khader SA, Gaffen SL, Kolls JK. Th17 Cells At the Crossroads of Innate and Adaptive Immunity Against Infectious Diseases At the Mucosa. Mucosal Immunol (2009) 2(5):403-11. doi: 10.1038/mi.2009.100

39. Shahrara S, Pickens SR, Mandelin AM, Karpus WJ, Huang Q, Kolls JK, et al. IL-17mediated Monocyte Migration Occurs Partially Through CC Chemokine Ligand 2/Monocyte Chemoattractant Protein-1 Induction. J Immunol (2010) 184 (8):4479-87. doi: 10.4049/jimmunol.0901942

40. Acosta-Rodriguez EV, Napolitani G, Lanzavecchia A, Sallusto F. Interleukins 1beta and 6 But Not Transforming Growth Factor-Beta are Essential for the Differentiation of Interleukin 17-Producing Human T Helper Cells. Nat Immunol (2007) 8(9):942-9. doi: 10.1038/ni1496

41. Wilson NJ, Boniface K, Chan JR, McKenzie BS, Blumenschein WM, Mattson JD, et al. Development, Cytokine Profile and Function of Human Interleukin
17-Producing Helper T Cells. Nat Immunol (2007) 8(9):950-7. doi: 10.1038/ ni1497

42. Hsi ED, Remick DG. Monocytes are the Major Producers of Interleukin-1 Beta in an Ex Vivo Model of Local Cytokine Production. J Interferon Cytokine Res (1995) 15(1):89-94. doi: 10.1089/jir.1995.15.89

43. Lasiglie D, Traggiai E, Federici S, Alessio M, Buoncompagni A, Accogli A, et al. Role of IL-1 Beta in the Development of Human T(H)17 Cells: Lesson From NLPR3 Mutated Patients. PloS One (2011) 6(5):e20014. doi: 10.1371/ journal.pone.0020014

44. Saraiva M, Vieira P, O'Garra A. Biology and Therapeutic Potential of Interleukin-10. J Exp Med (2020) 217(1):1-19. doi: 10.1084/jem.20190418

45. Cong Y, Oliver AO, Elson CO. Effects of Cholera Toxin on Macrophage Production of Co-Stimulatory Cytokines. Eur I Immunol (2001) 31(1):64-71. doi: 10.1002/1521-4141(200101)31:1<64::aid-immu64>3.0.co;2-p

46. Bagley KC, Abdelwahab SF, Tuskan RG, Fouts TR, Lewis GK. Cholera Toxin and Heat-Labile Enterotoxin Activate Human Monocyte-Derived Dendritic Cells and Dominantly Inhibit Cytokine Production Through a Cyclic AMPdependent Pathway. Infect Immun (2002) 70(10):5533-9. doi: 10.1128/ iai.70.10.5533-5539.2002

Conflict of Interest: The authors declare that the research was conducted in the absence of any commercial or financial relationships that could be construed as a potential conflict of interest.

Copyright (C) 2021 Akhtar, Nizam, Basher, Hossain, Akter, Bhuiyan, Qadri and Lundgren. This is an open-access article distributed under the terms of the Creative Commons Attribution License (CC BY). The use, distribution or reproduction in other forums is permitted, provided the original author(s) and the copyright owner(s) are credited and that the original publication in this journal is cited, in accordance with accepted academic practice. No use, distribution or reproduction is permitted which does not comply with these terms. 